\title{
THE PHILOSOPHY, DESIGN, AND TESTING OF A UNIFORM APPLIED LOAD FLAT PLATE TESTING MACHINE
}

\author{
A. QUIRK \\ UKAEA, Safety and Reliablitity Directorate, \\ Wigshaw Lane, Culcheth, Warrington WA3 $4 N E$, United Kingdom \\ C. E. CROOK \\ British Nuclear Fuels Ltd., Windscale Works, Sellafield, Cumberland, United Kingdom \\ The presence of a central crack, and its associated plastic zones may significantly \\ affect the distribution of the stress applied by a loading machine, to a teet plate. As a \\ result the fracture stress may be affected, usually optimiatically. Examples of these
}

\section{SUMMARY} effectg are discussed.

The design of a machine in which the load is uniformly applied to the test specimen is described and preliminary test data presented. Mild steel plate tested at ambient temperature has fractured at less than general yield. 


\section{Introduction}

The application of a fracture mechanios approach to the Safety Assessment of large structures requires the availebility of relevant data. Clearly the best data would be obtained by carrying out a series of destructive testa on the type of structure being assessed but in most caser, and particularly for large pressure vessels, this will be ruled out on grounds of cost and the potentially hazardous nature of the terte. An alternative method is to obtain fracture date from tests on flat plates containing central defects. Consequently it is essential that the effect of testing technique on the resultant data is understood. In this paper the effect of various veriables on fracture data obtained from flat plate tests will be considered, and their relationship to the case of terting an infinite plate examined. Various hypotheees are proposed and published data are presented to support them. In the second part of the paper the design of a novel flat plate teating machine is described in which it is suggested that the problems associated with current practice are overcome. Preliminary test results obtained from this machine are preaented. 2. Limitation of Current Flat Plate Testing Practice

Current practice in flat plate teating generally involves fracturing specimens containing a defect located transversely to the direction of the applied load. The load generated by the machine is usually applied to the specimen through rigid end pieces, additionally the ends of the specimen may be much thicker then the test section. The net effect is to apply a uniform overall exteneion to the plate rather than the desired uniformly distributed stress. This is of importance in that theoretical treatments assume that a uniform applied stress is applied to the specimen and this theory is then compared with fracture date obtained under constant applied deflection conditions, it will be seen later that such test data is invariably optimistic. Test data can also be affected by specimen size. These effects are discuseed below.

\subsection{The Influence of Loading Method on Fracture Deta}

A loading system which is rigid will tend to cause a depression in the strain/stress distribution along the top of a flat specimen containing a central crack transverse to the loading direction. This is because the loading plates, being rigid, constrain the top and bottom edges to remain parallel and conequently a uniform extension is applied across the length of the specimen. In the vertical central region of the plate most of this extension is absorbed in the highly strained regions at the crack tips. Whereas the extension will be more uniformly distributed along the vertical regions remote from the crack. Thus the strain, and therefore the stress, applied to the mid width region of the plate will be less than that applied towards the edges of the plate with the consequence that a plate to which such a load diatribution is applied will fail at a load higher than that which would be required were the load uniformly distributed. This is because for a given everage value of gross area stress, $\sigma_{g}$, the loading system with a streas depression will shed less load into the stress concentration region at each crack tip. Such a specimen will therefore require a higher value of $\sigma_{g}$ for the same load shedding capacity.

A typical arrangement for the testing of large plate is described in (1). The plate, with thickened ends, is attached to the machine with cheek plates and loading pins which are in turn fixed to two stiff cross beans with the result that the plate experiences a uniform overall extension. Typical applied strees distributions derived from atrain gauge measurements for half of a $2130 \mathrm{~mm}$ wide plate containing a $304 \mathrm{~mm}$ long defect are shown in 
Fig. 1. The strese levele for various groes loads are shown and an applied etrese depression above the defect can be seen. The relative magnitude of the depression increases as the overall load increaee日.

Similar results, shown on Fig 2, were obtained from testing $457 \mathrm{~mm}$ wide, $152 \mathrm{~mm}$ thicl. plates ${ }^{(2)}$. The atrain gauge readings at the maximum load of $33.6 \mathrm{WN}$ are shown at locations on the side of the plate and also at plate mid width. A significant strain depression is seen to have been induced by the.thick apeoimen ends and rigid loading aystem, the mid width strain being only about one third of the strain measured along the specimen edge.

Piotorial evidence of the stress depression is also available $(3,4)$. Here defected aluminium alloy sheets were coated with a strain sensitive lacquer and teated to failure. The lacquer between the crack and the loading pins was relatively unflawed whereas the lacquer along the edges of the specimen was heavily crazed, clear evidence of an applied stress depression.

\subsection{The Influence of Plate Longth on Bracture Data}

The magnitude of the applied stress depression that will occur in a epecimen with a rigid loading system will be dependent on the ratio of the total overall extension to the deformation occurring in the crack tip region. If thit ratio is large the stress depreseion will be small. One way to achieve this objective is to increase the specimen length. However a simple calculation will show that unacceptably long plates would be required.

Consider a defected plate of a $\mathrm{C}-\mathrm{Mn}$ steel at $-30^{\circ} \mathrm{C}$ for which a crack opening displacement of $0.64 \mathrm{~mm}$ would be required for fracture (5). Assume that the defect length is such that the plate fails at a uniform applied otress of $138 \mathrm{NN} / \mathrm{m}^{2}$ and assune that the COD must be only one fifth of the total deflexion across the plate to keep the magnitude of the mid width stress depression small. Thus an overall extension of $3.18 \mathrm{~mm}$ would occur and this would require a plate of $5 \mathrm{~m}$ length. This makes no allowance for the extension occurring in the plastic zones around the crack tips which if included, would indicate a plate length considerably longer than $5 \mathrm{~m}$. Clearly, machines to test plates of this length, and even longer plates would be required for more ductile materialø, would be considered unreasonable.

\subsection{Influence of Plate Thickness on Fracture Data}

Consider the situation where two plates, identical except for thickness are tested in the same rigid machine. Because of the triaxiality of the crack tip atress system the thicker plate will have a smaller amount of crack opening and will be subject to a smaller applied streas depression that will occur in the thinner plate. Consequently, other fracture parameters being equal, the thick plate will fail at a lower mean gross area atress than will the thin plate.

This is not to imply that plate thiokness does not have an effect on fracture, only that a machine is capable of producing an apparent thickness effect.

\subsection{Influence of Plate Width on Fracture Data}

The influence of plate width on fracture will be considered in the next section.

\section{A Theoretical Approach to the Analysis of Fracture Data}

In the last section it was suggested that the failure stress of a defected plate will not only be a function of ductility but also be affected by the plate dimensions and by the manner in which the plate is loaded. It was suggested that the data obtained may well be peculiar to the test and may not be directly applicable to a given practical aituation. A requirement therefore exists for some means by which data obtained from a given test can be 
analysed in terms of the teat parameters. The approach used in this paper is to assume a predictive equation which primarily takes into account a characteristic material dimension and then deciding what influence the test parameters will have on the predicted data.

3.1 The Influence of Plate width on Fracture Data

It has been demonstrated Eraphically (6) that Equation (1) is an adequate description of the fracture criterion for an infinite plate:

$$
\sigma_{u}=\sigma_{g}\left(\frac{a}{s}+1\right)
$$

where $\sigma_{u}=$ UTS, $a=$ half crack length, and $S=a$ material characteristic dimension, being the mean width of the stress concentration area, whose height is equal to $\sigma_{u}$ which arises at each crack tip.

This equation auggests that plate width $W$ is in itself not an important factor provided that the plate is sufficiently wide to accommodate the parameter $S$ within the ligament between the defect and the edge of the plate.

With the criterion for failure embodied in Equation (1), that is, at fracture a stress equal to the UTS of the material acts over a distance $S$ ahead of the crack tip, then if the ligament size $\left(\frac{W}{2}-a\right)$ is less than $S$, the stress on the ligament will be equal to the UTS, and fracture will occur, at a gross area stress less than that given by Equation (1). The failure will be described by a simple equilibrium failure criterion. That is:

$$
\sigma_{g^{*}} W=\sigma_{u} \quad(W-2 a)
$$

\subsection{A Grephical Representation of Failure Data}

The development of this paper is centred around Equation (1) although it should be noted that much of the argument would still follow if some other predictive equation were used. In fact only the discussion on plate width effect is dependent on the choice of prediotive equation.

The two failure criteria represented by Equations (1) and (2) are ohow graphically in Fig 3. One point on the graph will be fixed and common to both, at zero crack length the gross area stress at failure will be equal to the UTS. For all practical cases a further point is fixed, when the crack length is equal to the plate width the gross area gtress at failure will be zero.

The curve ABCDFJ is the curve represented by Equation (1). This is the suggested failure curve for a large plate with no loading abnormalities, the load being evenly distributed along both edges, and the plate being of sufficient width to eliminate any width effect.

The line AGH is the "UTS on net area" failure criterion given by Equation (2). For crack lengths less than that indicated by point F failure will lie on the Equation (1) curve, ABCDF. At point $F$ the craok length is equal to $(W-2 S)$. Hence for longer craoks Equation (2) will hold and the failure locus is given by FH. With decreasing plate width points $H$ and $F$ move towards the left thus increasing the length FH, and for very narrow plates where $W<2 S$ the failure locus AGH should be entirely below the curve ACJ.

Note that if flat plate fracture data is graphed as "gross area fracture stress $v$ crack length" then if a straight line plot results the failure criterion is that failure occurs at constant net area stress, the actual value of which is given by the ordinate intercept. This follows by writing $\sigma_{\text {net }}$ ingtead of $\sigma_{\mathcal{u}}$ in Equation (2). 


\subsection{The Fffect of Rigid Loading Plates on Fracture}

It has been suggested that a loading machine with rigid ends will cause a depression, along the loading boundary above the crack, in the applied stress distribution, and that the rigid ende will tend to keep the loading boundaries of the plate parallel.

A certain amount of deformation at fracture will be required in the material around the crack tip. The magnitude of this deformation will govern the strese depression and also by how much the plate boundaries must separate to accommodate this deformation. In general, i2 order to fracture a material exhibiting a marked yield point it will be necessary to atress the material to yield level so that this deformation may be accommodated. This is because relatively large deformations at constant stress occur at yield. Thil concept may best be illustrated by means of an example.

Consider test data (1) obtained on mild steel specimens, $1250 \mathrm{~mm}$ long. Such a specimen without a defect would extend by $1.4 \mathrm{~mm}$ overall, when subjected to yield level stresses. However when such a plate contains a defect the deformation occurring over a length of $25 \mathrm{~mm}$ at the crack tip is of this order. For example a test at $16^{\circ} \mathrm{C}$ on a $0.36 \% \mathrm{C}$ steel plate with a $305 \mathrm{~mm}$ defect showed $1.8 \mathrm{~mm}$ deformation over a $25 \mathrm{~mm}$ gauge length spanning the crack tip. Clearly then such a specimen must reach yield level, where significant deformation may occur, along some transverse section of the plate. The ligament is subject to the highest mean stress levels and it therefore seems probable that yield will oocur on this aection, and as this yield zone extends increased deformation can be accommodated with no significant increases in stress so that cracks opening by different amounts, that is different material ductilities, will fail at the same applied atress.

Thus a "yield stress on ligament" failure criterion has been postulated and is represented by the straight line BED, Fig 3 .

For materials with no marked yield stress the same argument would hold except that the net area stress at failure, $\sigma_{n}$, would be not so closely defined and would be dependent on material ductility and plate length.

\subsection{Summary of Possible Failure Modes}

It is suggested that the plot of gross area stress at failure versus critical crack length will take one of the following forms:

AGH - This is the UTS on net area failure criterion.

ACJ - This is the failure locus for plate in which boundary effects do not affect fracture.

ABCDFH - This should apply to a plate of finite width but uniformly loaded. At point $F$ the plate becomes too narrow.

ABEDFH - This should apply to a finite plate where a non-uniform load distribution te of significance over the region $B E D$.

\section{A Roview of Flat Plate Test Data}

In the limited space available it is not possible to present experimental data concerning the fracture of flawed plates, and thus to demonstrate that this data is described by one or more of the failure modes discussed in Section 3.5. However one graphical plot conforming to each type of fracture mode will be presented, a more comprehensive survey is available in (6).

4.2 Fracture Data Showing Failure by "UTS on Net Area"

Fig 4 showe fracture data obtained on a $\mathrm{Ni} \mathrm{Cr}$ Mo V ateel using test pieces $25.4 \times 25.4 \mathrm{~mm}$ 
with central cracke. The UTS of the material was $1020 \mathrm{MN} / \mathrm{m}^{2}$. The linear form, with an ordinate intercept equal to the UTS, is consistent with a "UTS on net area" failure criterion.

\subsection{Fracture Data Showing Failure by "Yield Stress on Net Area"}

Figure 5 illustrates tests on three different sizes of mild steel test plates. The linear plot shows that, except for very short defects, failure occurs by a "yield stress on net area" failure criterion. This failure mode occurs so frequently in the testing of mild steel that statements have been made that the attainment of general yield is a necessary failure criterion. Thus the results of 177 tensile tests on artificially notched mild steel plates were summarised: ".....it can be stated that the tests of notched shapes, cut from prime plate showing usual ductility in the tensile tests, have one thing in common. When tested at temperature so that notch brittle fracture occurs, failure does not take place until loads sufficient to cause general yield are applied and the general yield zone embraces the root of the notch". and viz: "..... Hundreds of tests from 1942 onwards have shown that plates of undamaged stmuctural steel with even the longest and sharpest cracks and temperatures below brittle transition do not fracture in central static loading unlegs the net nominal stress reaches or exceeds yield level".

\section{4 summary}

The overall conclusion that emerges from the above evidence is that a considerable amount of flat plate test data has been obtained under conditions that mask the true effect of crack length on the fracture resistance of a plate.

\section{Design and Use of Flat Plate Testing Machine}

\subsection{Introduction}

The arguments in this paper suggest two major reasons why the fracture data for ductile materials obtained from conventional test machines may be of limited practical value. First the plate tested may not be sufficiently large to accommodate the material characteristic dimension, $S$, and secondly the load distribution produced by a particular machine may be quite different to that found in the practical situation to which the data is being applied. It has been suggested that both of the effects will influence the fracture data obtained from a conventional machine, and the data will, in general, tend to be optimistic.

In an attempt to overcome these difficulties, particularly those associated with an uneven load distribution, a novel large flat plate testing machine has been designed and manufactured.

\subsection{The Flat Plate Testing Machine}

The form of the specimen is shown in Fig 6. The test plate is welded into re-usable end pieces so that the resulting form is a large I beam with very thick flanges, the web of the beam containing both the test plate and part of the end pieces. The flanges are not continuous but are formed from a series of $178 \mathrm{~mm}$ wide slabs out from $76 \mathrm{~mm}$ thick plate standing on edge. This gives the desired effect of a slotted flange and has the advantage that the weaker thickness direction of the plate does not have to transmit any load. The 'slots' are continued into the web section of the test pleces.

The test plate is loaded by a series of hydraulic jacks and thrust plates, a pair of jacks acting on each flange section through spherical bearings with one jack on each side of the test plate. The jacks are connected to a common source of hydraulic pressure. By loading the plate in this manner the total applied load is spread evenly among the jacks and thus 
distributed evenly along the test plate, thus achieving the design objective.

The final arrangement is shown in Plate I in which a strain gauged $51 \mathrm{~mm}$ thick test plate is in position ready for testing.

\subsection{Advantages of the System}

It is felt that this system has a number of advantages. These are es follows:

5.3.1 A variable load distribution can be applied to the test plate. As described above the system is arranged to apply a uniform load distribution but by varying the pressure in individual jack pairs any load distribution may be applied.

5.3.2 The system is flexible. The plate width can be adjusted aimply by varying the number of flanges and using an appropriate number of jacks.

\subsubsection{The machine is compact.}

5.3.4 The rig can be converted if necessary into a bi-axial stressing unit. Transverse loading could be applied in a similar manner to the longitudinal loading with jacks either between the longitudinal jacks and test plate or external to the longitudinal jacks, their position depending on the required longitudinal/transverse atress ratio.

5.3.5 The machine is relatively inexpensive. This is in part due to the fact that the loading system is in compression allowing the use of steel castings.

\subsection{Preliminary Testing - Results}

Nine tests have been carried out, of these six tests were on specific weld/parent plate combinations. Of the others two tests were carried out at ambient temperature on mild steel plate, and are relevant to this discussion. The test data presented in Table I shows that both tests failed at a gross area stress less than general yield, moreover in both cases the fracture surfaces were flat with minimal evidence of yielding. The fracture surfaces for test plate 11, with a measured Charpy $V$ energy of 69J, are shown in Plate 2.

The predicted gross area fracture stresses using Equation (1) are included in Table I.

\section{Table I - Flat Plate Test Data}

\begin{tabular}{|c|c|c|}
\hline & Teat Number 3 & Test Number 11 \\
\hline UTS $\mathrm{mN} / \mathrm{mm}^{2}$ & 426 & 482 \\
\hline Yield stress $\mathrm{MN} / \mathrm{mm}^{2}$ & 255 & 248 \\
\hline Nlongation $\delta,(G L=4 \sqrt{A}) \%$ & 36 & 37 \\
\hline Charpy V Inergy (ф), J & 10 & 69 \\
\hline Plate thickness mm & 48 & 51 \\
\hline Plate width, $\mathrm{mm}$ & 820 & 820 \\
\hline Crack size, mm & 178 & 279 \\
\hline Cross area stress, $\left(\sigma_{G}\right) \cdot \mathrm{MN} / \mathrm{mm}^{2}$ & 166 & 197 \\
\hline Predicted*, $\sigma_{g} . \mathrm{MN} / \mathrm{mm}^{2}$ & 157 & 206 \\
\hline
\end{tabular}

* Using Fquation (1) where $S=1.9 \times 10^{-3} \delta^{2} \phi^{\frac{1}{3}}$ in metric units, Ref 11

\section{Summary}

A machine for testing large flat plates in which the load is evenly distributed across the plate has been designed and manufactured. Initial results from this machine have demonstrated that $54 \mathrm{~mm}$ thick mild steel plate tested at ambient temperature will fail, at stresses less than general yield, with flat fracture surfaces showing little evidence of ductility.

The fracture stresses were in close agreement with predicted values. 
(1) QUIRK A et al. Nucl, Fng. and Design, Vol. 4, 1966

(2) HSST program semi-annual progresa report for period to $28 \mathrm{Feb} .1970$. ORNL 4590

(3) GOLFSTANHA A A. Min. of Supply S \& T Memo $27 / 57$

(4) WILLAMS D. RAE Tech. Note Structures 289

(5) KIRBY $\mathbb{N}$ et al. 2nd Int. Conf. PV Tech. San Antonio 1973

(6) QUIRK A and CROOK C. UKAEA SRD R 61

(7) DECHAENE $R$ and BECKMAN R. IIW - X538 - 69

(8) LANDES J D and BEGLEY J A. ASTM. STP 514

(9) WELLS A A. Welding Res. April 1953

(10) MYLONAS C. Pressure vessels and piping design analysis Vol. 1, p 271-2 ASME

(11) QUIRK A. OECD, CSNI Specialist Meeting on Fracture Mechanics. Daresbury (UK), 22-24 May 1978.

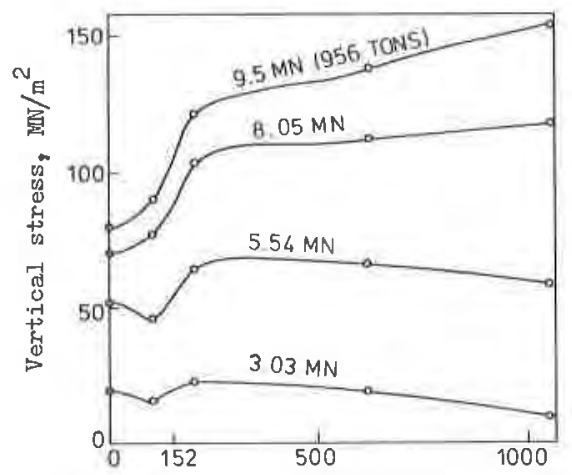

Pig. 1. Stress distribution applied to test plate by $40 \mathrm{Mn}$ (4000 ton) machine. Half crack length $=152 \mathrm{~mm}$ (Ref. 1). Note that this plate did not fracture, at a higher fracture load the depression would have been even more pronounced.

Distance from vertical centre line, mm

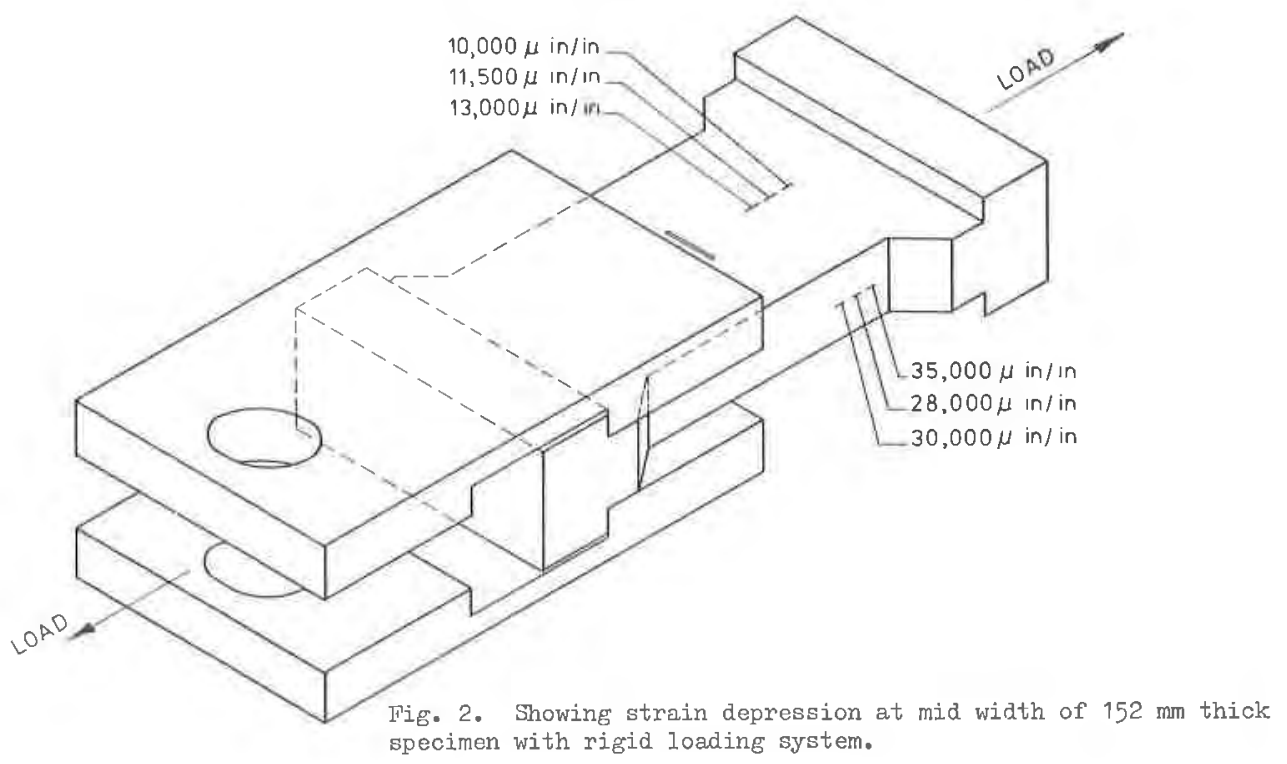


Vonge: wa med $\mathrm{pin}$-looded pestes $4 / \mathrm{w}=3$

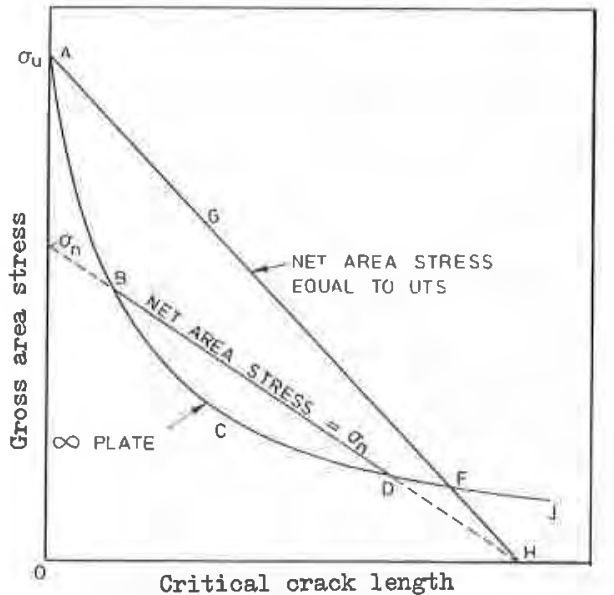

Fig. 3. Fossible failure loci in a flat plate teat.

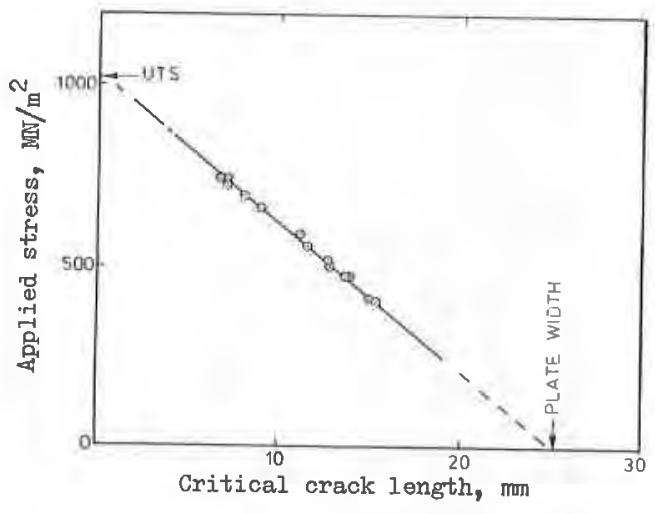

Fig. 4. Fracture data on Ni Cr MoV steel specimens showing failure mode of UTS on ligament. UTS $=1020 \mathrm{MN} / \mathrm{m}^{2}$, test piece $25.4 \mathrm{~mm}$ wide $\times 25.4 \mathrm{~mm}$ thick (Ref. 8).

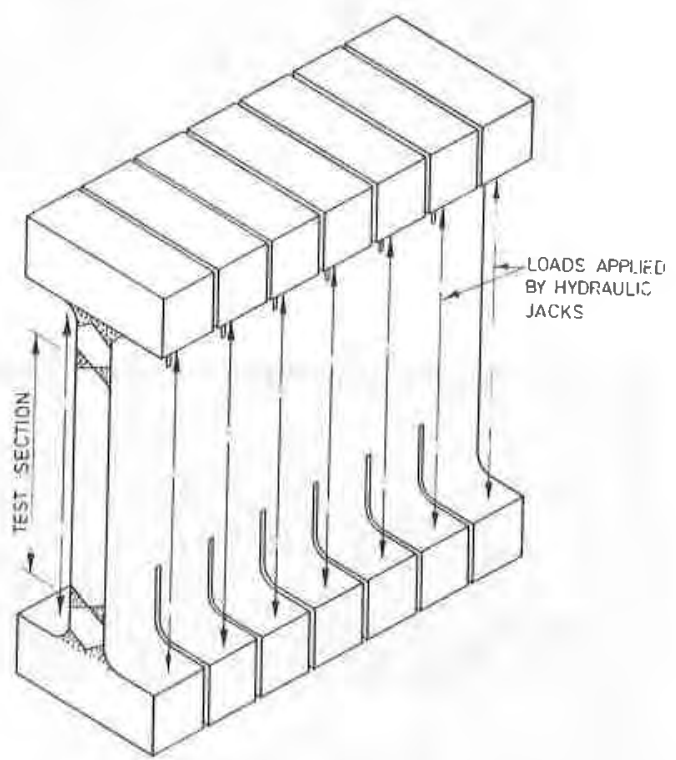

Fig. 6. Schematic drawing of uniformly diatributed applied load machine. 


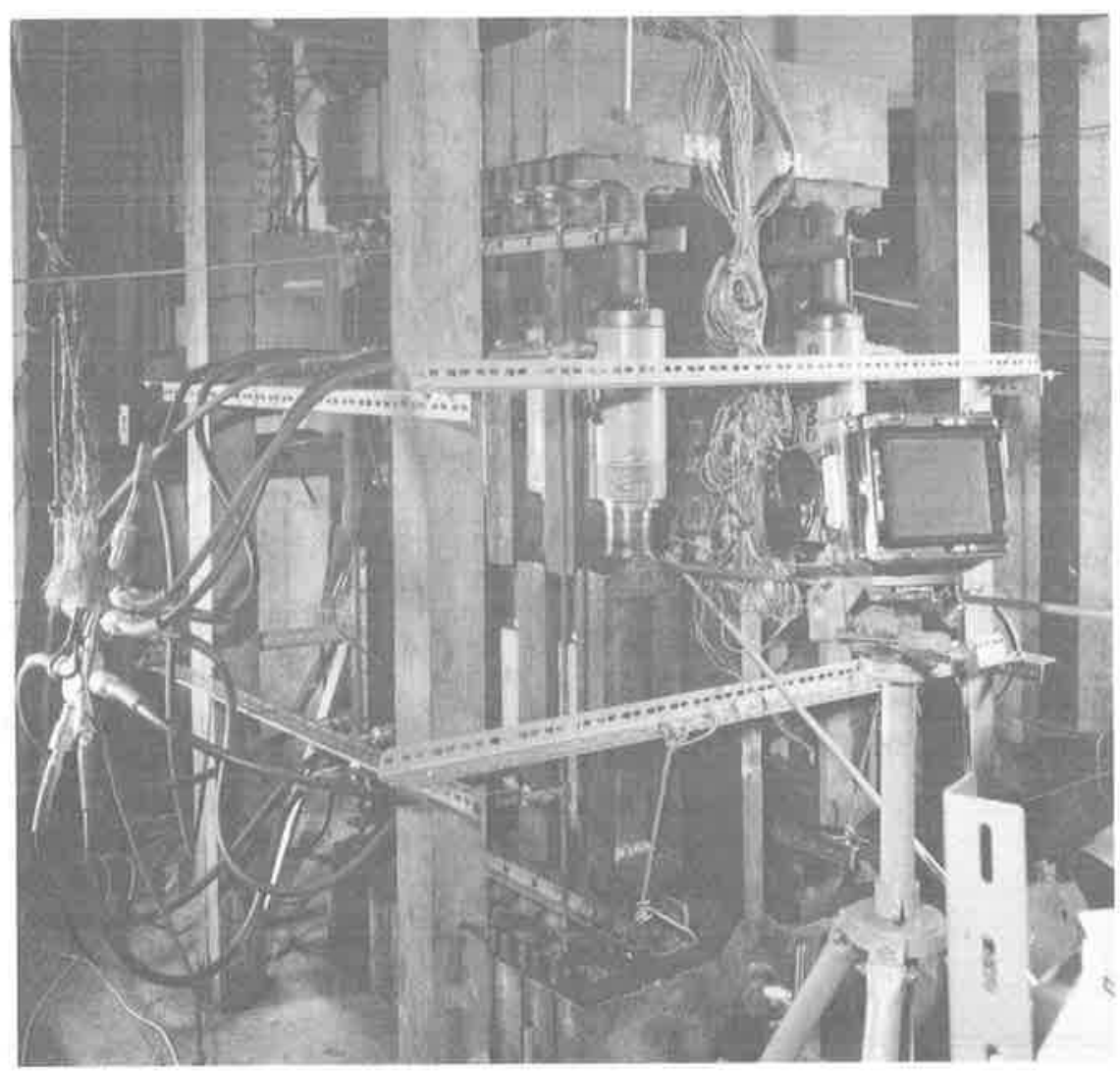

Plate 1 - Test rig with strain gauged $51 \mathrm{~mm}$ thick test plate

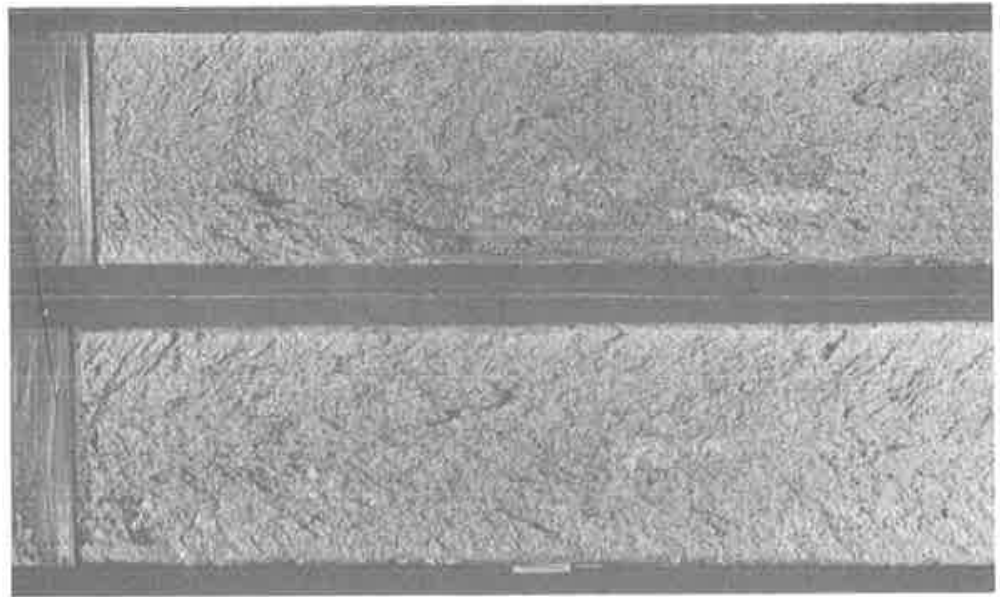

Plate 2

Fracture appearance of test plate 11 . Charpy $V=69 \mathrm{~J}$. 